though pain limits the amount which can be given intramuscularly. Sputum levels are much lower than those in blood (J. R. May, personal communication, 1969). The drug must therefore also be given by aerosol in order to attain sufficient intrabronchial concentration.

In patients with renal failure (all our patients had blood ureas below $60 \mathrm{mg} . / 100 \mathrm{ml}$.) carbenicillin alone might be the safest treatment available (Eastwood and Curtis, 1968).

We thank the nursing and secretarial staff of Ware Park and the Herts and Essex Hospitals; Dr. W. D. Linsell and Dr. W. Mavor and staff, Pathology Laboratory, Hertford County and Herts and Essex Hospitals; Dr. E. T. Knudsen, Beecham Research Laboratories, for supplies of carbenicillin; Professor J. W. Crofton, Uni- versity of Edinburgh, for criticism; and the physicians who sent us their patients.

REFERENCES

Brumfitt, W., Percival, A., and Leigh, D. A. (1967). Lancet, 1, 1289.

Burns, M. W., and May, J. R. (1968). Lancet, 1, 270.

Cooper, R. G., Rice, J. C., and Penfold, J. L. (1969). Medical fournal of Australia, 1,517

Eastwood, J. B., and Curtis, J. R. (1968). British Medical fournal, 1, 486.

Halliday, N. P. (1967). Clinical Trials fournal, 4, 771.

Knudsen, E. T., Rolinson, G. N., and Sutherland, R. (1967). British Medical fournal, 3, 75 .

Mariani, G., and Velluti, G. (1969). Paper read at the 6th International Conference of Chemotherapy, Tokyo.

Pines, A., Raafat, H., and Plucinski, K. (1967). British Medical fournal, 2, 543.

Stratford, B. C. (1968). Medical fournal of Australia, 2, 890.

\title{
Increased Sebum Excretion in Patients with Breast Cancer
}

\author{
J. L. BURTON,* M.B., B.SC., M.R.C.P. ; W. J. CUNLIFFE, † M.B., B.SC., M.R.C.P. ; SAM SHUSTER, † PH.D., M.B., F.R.C.P.
}

British Medical fournal, 1970, 1, 665-666

Summary: The rate of sebum excretion from the fore$N$ head skin of patients with early breast cancer was found to be just significantly higher than in age-matched control women. This may indicate that some breast cancer patients have an increase in circulating or tissue-bound sebotrophic hormones, or a decrease in their inhibitors.

\section{Introduction}

A variety of exogenous steroid hormones and ablative endocrine procedures are known to affect the course of advanced breast cancer, but the response in an individual case is relatively unpredictable (Stoll, 1969). In view of the present uncertainty regarding the hormonal status of patients with breast cancer it is relevant to study the activity of other organs known to be under hormonal control. Krant et al. (1968) found a seborrhoea in patients with advanced breast cancer, and we have compared the sebum excretion rates in patients with early breast cancer and a matched group of control subjects.

\section{Method and Subjects}

The sebum excretion rate was measured by the method of Strauss and Pochi as modified by Cunliffe and Shuster (1969a).

In all subjects three-hour sebum collections were done at the same time in the afternoon, from two equal areas of skin at opposite sides of the forehead. Sebum collections were made preoperatively on patients after their admission to hospital for biopsy of a lump in the breast which was clinically suspected to be early carcinoma. Twenty patients (aged 42 to 75 years) were found at operation to have breast cancer. None of them had evidence of metastasis, and none had received hormonal therapy. As control subjects we used age-matched women from the medical wards who were convalescing from benign diseases such as acute bronchitis, peptic ulcer, acute pyelonephritis, cerebral thrombosis, etc. None of these patients was pyrexial and none was known to have any endocrine dysfunction. Because of our recent finding (Cunliffe and Shuster, $1969 \mathrm{~b}$ ) of the importance of a previous history of adolescent acne in the interpretation of sebum excretion rates in subsequent years all patients were asked about previous acne and

* Senior Registrar, Royal Victoria Infirmary, Newcastle upon Tyne. † Consultant Dermatologist, Leeds General Infirmary.

F Professor of Dermatology, Royal Victoria Infirmary, Newcastle upon Tyne NE1 4LP. were examined for acne scarring. We made no attempt to match patients with regard to acne as this could have masked a difference in hormonal status in the two groups. Six of the cancer patients and five of the controls were premenopausal.

\section{Results}

The results are given in the Table. The mean sebum excretion rate was $0.61 \mu \mathrm{g} / \mathrm{sq} . \mathrm{cm} . / \mathrm{min}$. \pm 0.07 in the cancer patients and $0.42 \mu \mathrm{g} . / \mathrm{sq} . \mathrm{cm} . / \mathrm{min} . \pm 0.08$ in the control group. The mean difference between cancer patients and their paired controls was $+0 \cdot 19$, and this difference was just significant $(\mathrm{p}<0.05, t$ value with 19 D.F. $=2.15$ ).

Sebum Excretion Rates. Each Rate is the Mean of Two Observations, One From Each Side of the Forehead

\begin{tabular}{|c|c|c|c|c|c|}
\hline \multirow{2}{*}{$\begin{array}{l}\text { Age of } \\
\text { Patient }\end{array}$} & \multicolumn{2}{|c|}{$\begin{array}{l}\text { Sebum Excretion Rates } \\
(\mu \mathrm{g} . / \mathrm{sq} . \mathrm{cm} . / \mathrm{min} .)\end{array}$} & \multirow{2}{*}{$\begin{array}{l}\text { Age of } \\
\text { Patient }\end{array}$} & \multicolumn{2}{|c|}{$\begin{array}{l}\text { Sebum Excretion Rates } \\
(\mu \mathrm{g} . / \mathrm{sq} . \mathrm{cm} \cdot / \mathrm{min} .)\end{array}$} \\
\hline & Cancer & Control & & Cancer & Control \\
\hline $\begin{array}{l}42 \\
45 \\
47 \\
50 \\
50 \\
50 \\
52 \\
52 \\
55 \\
57\end{array}$ & $\begin{array}{r}0.97 \\
0.69 \\
+1.11 \\
0.71 \\
0.39 \\
0.33 \\
01.03 \\
0.60 \\
0.90 \\
0.66\end{array}$ & $\begin{array}{l}0.22 \\
0.36 \\
0.33 \\
0.41 \\
0.56 \\
0.19 \\
1.06 \\
0.43 \\
\begin{array}{l}1.33 \\
1.01\end{array}\end{array}$ & $\begin{array}{l}58 \\
58 \\
59 \\
64 \\
64 \\
64 \\
65 \\
67 \\
70 \\
75\end{array}$ & $\begin{array}{l}0.67 \\
0.09 \\
0.35 \\
0.75 \\
0.32 \\
0.37 \\
0.56 \\
1.16 \\
0.29 \\
0.32\end{array}$ & $\begin{array}{l}0.60 \\
0.40 \\
0.34 \\
0.03 \\
0.13 \\
0.09 \\
0.33 \\
0.10 \\
0.18 \\
0.37\end{array}$ \\
\hline
\end{tabular}

*Previous acne

\section{Discussion}

Our finding of an increased rate of sebum excretion in patients with breast cancer is in agreement with the finding of Krant et al. (1968). We would emphasize, however, that the significance of the difference between our patients with breast cancer and the paired controls is not great.

The difficulty of obtaining suitable controls for breast cancer patients has been discussed by Bulbrook and Hayward (1969). Little is known of the effect of factors such as apprehension and prolonged illness on sebaceous activity. The ideal subjects for our control series would have been women admitted for biopsy of benign breast disease, but as it was not possible to obtain age-matched subjects relatively "fit" medical patients were used. It is apparent that our results will need further confirmation in a larger series of cases, preferably with several control series from different sources. 
The figures of Krant et al. (1968) for sebum excretion rate are expressed as mg. sebum/10sq.cm./3 hours, but after conversion to $\mu \mathrm{g} . / \mathrm{sq} . \mathrm{cm} . / \mathrm{min}$. their value for the mean excretion rate in postmenopausal control subjects $(0.57 \pm 0.06)$ was fairly close to our control figures $(0.42 \pm 0.08)$. Their value for control subjects also lies between our previous figures for normal women aged $\mathbf{4 0}$ to $\mathbf{7 0}$ years with and without previous adolescent acne-namely, $0.84 \mu \mathrm{g} . / \mathrm{sq} . \mathrm{cm} . / \mathrm{min} . \pm 0.07$ and $0.23 \mu \mathrm{g} . / \mathrm{sq} . \mathrm{cm}$./min. \pm 0.06 (Cunliffe and Shuster, 1969b). The sebum excretion rate in Krant's patients with advanced cancer $(1.17 \pm 0.16)$ was significantly higher than our value for patients with early cancer $(0.61 \pm 0.07)$. It is possible, therefore, that this represents a change in hormonal status as the cancer progresses, though methodological differences may be important. Another possibility is that, owing to chance sampling differences, more of their cancer patients had the persistent seborrhoea which is associated with previous adolescent acne.

The seborrhoea found in patients with breast cancer may be of relatively recent onset, but alternatively it may have been present for many years, in which case one might find an increased incidence of adolescent acne in women who later tend to develop breast cancer. Only two of our cancer patients and one of our control patients gave a history of acne, and since the incidence of acne in the adolescent female population in this district is at present in the region of $50 \%$ (Burton et al., 1969) it seems likely that little reliance can be placed on our patients' memories in this respect. It is notable that the three patients who did give a history of acne all had seborrhoea, and it is probable that only the more severe grades of acne are remembered into middle age.

None of our patients had acne scarring, and it seems unlikely that the incidence of previous severe acne in our breast cancer patients was increased. These facts, together with the possibility of a greater seborrhoea in advanced than in early cancer, suggest that the increased sebum excretion is of recent onset and is progressive. Prospective studies will be required to test this idea.

The cause of this slight but significant increase in sebazeous gland activity is unknown. The sebaceous glands are righly sensitive to androgenic stimulation, and though oestrogens produce a decrease in sebaceous activity, the effect of even larger doses of oestrogen is prevented by the simulta- neous administration of small doses of androgen (Strauss et al., 1962). Bulbrook and Hayward (1967) observed that women who subsequently developed breast cancer had an abnormality of urinary steroid excretion which was multidirectional-that is, the variance was increased-though the trend was towards a subnormal excretion of androgen metabolites. This is difficult to reconcile with our finding of an increased sebum excretion in women with breast cancer, unless some other factor is operative. There is evidence for the existence of a pituitary sebotrophic factor in animals (Lasher et al., 1955; Lorincz and Lancaster, 1957), but its role in man is unknown.

The possible causes of seborrhoea include increased levels of circulating or tissue sebotrophic hormones, or an enhanced end-organ response to such hormones. Alternatively, there may be decreased inhibition of sebaceous gland activity either by decreased levels of circulating or tissue inhibitors such as oestrogen or by diminished end-organ response to inhibition. Further study is required to elucidate the mechanism concerned, and particular attention should be given to the relation between sebaceous gland activity and the subsequent clinical course of the breast cancer, especially with regard to response to hormonal therapy.

Thanks are due to many of the physicians and surgeons of the Newcastle Royal Victoria Infirmary for permission to study patients under their care; to Mr. D. Weightman, of the Nuffield Department of Industrial Health, the University of Newcastle upon Tyne, for statistical advice; and to Mr. Ian Cartwright for technical assistance. We are indebted to the Research Committee of the Newcastle Royal Victoria Infirmary for a generous grant to one of us (W.J.C.).

\section{REFERENCES}

Bulbrook, R. D., and Hayward, J. L. (1967). Lancet, 1, 519. Bulbrook, R. D., and Hayward, J. L. (1969). Lancet, 1, 1161 . Burton, J. L., Cunliffe, W. J., Stafford, I., and Shuster, S. (1969), Unpublished. Cunliffe, W. J., and Shuster, S. (1969a). British fournal of Dermatology,
81, 697.

Cunliffe, W. J., and Shuster, S. (1969b). Lancet, 1, 685.

Krant, M. J., Brandrup, C. S., Greene, R. S., Pochi, P. E., and Strauss, J. S. (1968). Nature, 217,463 .

Lasher, N., Lorincz, A. L., and Rothman, S. (1955). foumal of Investigative Dermatology, 24, 499 .

Lorincz, A. L., and Lancaster, G. (1957). Science, 126, 124.

Stoll, B. A. (1969). British Medical fournal, 2, 293.

Strauss, J. S., Kligman, A. M., and Pochi, P. E. (1962). fournal of Investigative Dermatology, 39, 139.
There are seven species of scorpions in Trinidad. These belong to the families Chactidae and Buthidae (Kjellesvig-Waering, 1966). The Tityus trinitatis (Pocock, 1894) of the Buthidae

* Lecturer in Medicine and Consultant Physician, Eastern Caribbean Medical Scheme, the University of the West Indies, General Hospital, Port-of-Spain, Trinidad, West Indies. family is the commonest scorpion in the island, accounting for almost $90 \%$ of the scorpion population. It is commonly found in forests under logs or debris, in sugar-cane fields, in banana, cocoa, and coconut plantations, and somotimes even in houses, mainly in the rural areas. Fatalities from scorpion stings, which occur only rarely, are more common in young children than in adults. Despite its aggressive appearance the scorpion is a shy creature and will use its sting only when roughly handled or trodden on. Nevertheless, there is a high incidence of scorpion stings in Trinidad. In the two months of July and August over 30 cases were admitted to the university unit of the Port-ofSpain General Hospital. Most of these had been referred from the small district hospitals of Arima and Sangre Grande, which serve a rural population. The most striking observation was the very high incidence of acute pancreatitis following the sting of the $T$. trinitatis. No previous reports have described this complication resulting from the sting of any other scorpion in the world. 